\title{
Pairing High School Teachers with Historically Black College \&University (HBCU) Computer Science Students to Teach Advanced Placement Computer Science Principles
}

\author{
Kinnis Gosha Ph. $\mathrm{D}^{1}$, Nathan Harris ${ }^{2}$, \\ ${ }^{1}$ Associate Professor, Morehouse College \\ ${ }^{2}$ Student, Morehouse College
}

\begin{abstract}
Reports have shown the lack of African Americans who take and pass the Advanced Placement (AP) Computer Science (CS) course. Many times, African American students are enrolled in schools that do not offer computer science courses like AP Computer Science. Interventions are needed nationally to provide African American students with equal opportunity to learn computer science. The goal of this research paper is design a study that will evaluate the effectiveness of a program to train high school teachers to teach Advance Placement Computer Science Principals using HBCU students majoring in computer science. Additionally, this program will be evaluated by its effectiveness to train teachers, its effect on the HBCU students who instruct the teachers and it feasibility to be scaled to HBCUs around the nation.
\end{abstract}

\section{Introduction}

There have been many initiatives designed to address the problem of low representations of African Americans in CS. According to data from the U.S. Census Bureau (2015), Blacks and African Americans make up $13.3 \%$ of the U.S. population, yet only $4.6 \%$ of graduate in CS at the Bachelor's level.[5]This program is creating a pipeline to increase the number of minority students, primarily African American students, pursuing and later graduating with a CS degree by utilizing the $81 \%$ of African Americans enrolled in the APS system.[6] This paper will reflect how the use of this program can build the capacity for teachers to teach a new AP computer science by using undergraduate mentors. The concept of pairing high school teachers with HBCU Computer Science students to teach a new Advanced Placement Computer Science Principles course is a hybrid program aimed in increasing the number of underrepresented minorities, particularly African Americans, entering computing careers. APCSP is a new AP course that introduces students to the foundational concepts of computer science (CS) and challenges them to explore how computing and technology can impact the world.[2]

In the United States, there are K-12 CS Framework's that literate students to fully engage in core concepts of computer science. [4] This program is aimed at building the capacity to teach high school teachers this course, to further increase the pipeline of students entering CS related careers.In a survey byover 100 college and university computer science department chairs and professors, $88 \%$ believe the course is a collegelevel computing course, $86 \%$ indicated they would award college credit and $70 \%$ indicated they will be offering a comparable course. [2] The primary research question seeks to find, how effective can there be aprogram that leverages HBCU CS majors to train high school teachers inteaching AP CS Principals in their school? Additional research questions revolve around the effect of this program on the HBCU computer science majors that participate in the program and the ability to scale the program to other HBCUs. By preparing CS students from local HBCU's they will have the capacity to teach teachers this APCSP curriculum. Those student mentors will be equipped with CS concepts and the APCSP curriculum, so that they can create an adaptive learning environment where teachers take the program experience and apply it to their classrooms. The big vision for this initiative is to create a collaborative network of HBCUs that will provide teacher professional development in CS in respective local school districts. Many of these local school districts and communities include a high population of high African American student's that are in economically challenged backgrounds. For example, Atlanta (Morehouse College, Spelman College and Clark Atlanta University) and Washington D.C. (Howard University) are major cities with high poverty status by school enrollment. [7] There can be several benefits for the HBCUs who take part in this initiative. One benefit is increase in thenumber of students who attend their schools to pursue computer science. Additionally, these students would come in with more computing experience, which would possibly increase the likelihood of students pursuing the major. Strategically, this program is designed to create an overabundance of teachers who can teach AP CS principles. This approach creates a pool of teachers who can later be recruited to teach AP Computer Science. It also provides broader skill sets that could potentially be applied to other courses they may be teaching. to those teachers which may 
enhance their future career options if they leave their school. Lastly, it will create a community of peers in which participating teachers can support each other.

\section{Literature Review}

Advanced Placement courses have been offered in high schools throughout the United States since the late 1950's and they have continued to create programs to meet the needs of the time. Due to the many technological advancements, computing related knowledge is becoming required by many industries. In 2016 alone, there were 4,810 schools that offered AP Computer Science A (APCSA), which at the time was the only CS course offered by the College Board. [3] APCSA is compatible with many CS Programming I courses in colleges and universities, which aligns with AP goal to prepare students to pursue college-level studies with the opportunity to earn college credit. [3] Students who complete this course would have covered concepts dealing with Object-Oriented Programming, program analysis, data structures and algorithms and understanding social implications of computer use. [3] Out of the 4,810 schools that offered the course in 2016, a total of 57. 937 students were enrolled in the program which is an $18 \%$ increase from the previous year in 2015.[3] We see that there is a need to further contribute to that increase in high schools offering college level CS course by the implementation of the program. The problem that needs to be addressed is out of all those students taking it, how many earn a 5 or above especially African American students. In 2016, the mean AP score for African American students on a 1 (No recommendation) -5 (Extremely well qualified) scale, was a 2.02 (Possibly qualified), and out of the 2027 African Americans that took the course, 112 of them earned a 5 on the exam.[3] In the state of Georgia alone, 8 African American students received a 5 on the exam. [3] Thus, the passing rate of African American students nationwide is 1\%, who took APCSA.

As aforementioned, there is a growing interest in students interested in computing related industries. Additionally, there is a small conversion rate of those furthering their studies in CS which is dependent on student passing their $1^{\text {st }}$ year CS courses. Therefore, the creation of APCSP was to move from such a heavy objected oriented course, to a course that introduces students to the central ideas of CS, inviting them to develop the computational thinking vital for success across multiple disciplines.[2] APCSP focuses on "fostering students to be creative" and encourages them to apply creative processes when developing computational artifacts. [2] We hypothesized that by training teachers using HBCU CS students to teach this course, they will be able to teach this new AP course in an environment that stimulates the students to reach their fullest potential as a computer programmer. The teachers are not limited to choosing a programming language because the course provides the freedom for teachers to create their own course that is centered around computer concepts within the curriculum.[2] With the curriculum, it is centered around computational thinking practices. These practices help students coordinate and make sense of knowledge to accomplish goals and task set throughout the course.[2] Included in the curriculum, there are connecting computing practices, creating computational artifacts, abstracting, analyzing problems and artifacts, computer communication practices and there are a variety of collaboration projects students will be indulged with.[2]

Essentially, by focusing on things like collaboration, computational thinking and problem solving, the course reflects that of the computer industry. Students in the course are encouraged to collaborate with others on projects and to analyze problems that effect industry production. By the implementation of this program, the aim is to provide teachers with the materials and understanding on how to teach the course. This could potentially lead to increasing the percentage of African American students receiving a 5 on the end of the year exam. APCSP course could be a gateway to students entering CS programs. Additionally, students will be better prepared for entering AP CS A, because of their better understanding of computational thinking. According to College Board AP Program, select universities offer students course credit for earning a 4 or 5 on the exam. [2]

\subsection{Undergraduate Student Recruitment}

\section{Program Design}

African American male and female undergraduate students would be recruited from the computer science program at their institutions. Communication efforts to distribute the initiativewill include but are not limited to: email campaigns, campus fliers, and in-class announcements.Students who express their interest will be required to attend an informational session that will provide the overall program overview. Here students will learn about program expectations, specifically the 3-semester commitment, 3.0 GPA requirement and a semester stipend. The application will be placed on the perspective website of that school's computer science department.Once the application period closes, applications will be reviewed by a select group of advisory board members comprised of computer science faculty members and the department chair.Project leadership will review applications and accept undergraduates based upon merit (completion of Programming I and II with a B or better), desire to participate, and availability.Seniors and freshmen will be excluded from the program based on pre-requisite requirements and availability to complete the program, respectively.Once selected, students will be required to sign a document that declares their commitment to the program. 


\subsection{Undergraduate Student Professional Development}

Once selected, the HBCU CS students selected to the program will attend a kickoff meeting to review the program, schedule and responsibilities. These students will have opportunities to collaborate with each other during weekly meetings with their Program Advisor (PA). These meetings will allow students to address concerns and communicate upcoming units in the APCSP course. During a 2-month period, students must complete the APCSP course while documenting their progress. Students will use their online portfolio (Mobile APCSP Google Site), to document their completed task and benchmarks when traversing through the 10 Units in the APCSP course. Students will use the site additionally to address any challenges or confusion experienced throughout each unit, that can be further discussed during the weekly meetings with the program participants and advisor.

Students will be encouragedto develop creative ways to better enhance teachers understanding for difficult subject matter when they are going through the course. They can do this by taking critical notes when completing the individual units within the APCSP course online. The PA will provide strategies that will reinforce strategic ways of tackling various problem areas throughout the online course.Students maintaining a disciplined schedule with deadlines will be able to keep up with the intensity of completing all the 10 units in a 2-month time frame. Once the 2-month period is over, the PAwill examine their finished portfolio that is completed when finishing the course. After completing the training, students must take and pass an AP CS Principles examination. Students will continue to prepare and retake the exam until they earn a score of 5 (out of 5 ) on this exam. They will then be notified if they are selected to serve as mentors in the program based off their results at the end of taking the APCSP course and there score on the AP exam.

\subsection{Teacher Recruitment}

Apart of the program, there on computer science faculty will serve as a liaison to the local school district. The objective is for there to be at least 1 academic teacher from each high school that will participate in the program. This selection will come from a recommendation from that high school's principal. The PA liaison will help identify teachers (a) without extensive extracurricular commitments during the Spring semester (e.g., coaching, graduate school, etc.); (b) who have been in the same school for at least 3 years to minimize attrition; (c) with a history of good performance on standardized exams to avoid misconduct during periods of testing; (d) currently not on a Personal Development Plan (PDP) or provision. Once those teachers are identified, an information session will be planned to give teachers and practitioners more information about the program. The session logistics will be shared with teachers by the PA liaison, who can then answer any additional follow up questions. In that session, teachers will be given the web address for the web application to acquire more information and to apply for the program. The PA liaison should have an awareness of the district needs and focuses, so that the selection of teacher participants will be the most beneficial at their respective schools. The PA liaison will lead the teacher selection committee (along with the other PAs and select members of an advisory board created by the CS department) that will create the final list of teacher participants. Selection factors include support from school principal, interest in teaching CS, prerequisite knowledge/experience, experience with online independent learning, currently taught courses, interest in possibly teaching AP CS, access to a personal computer, familiarity with technology, student composition at their schools and current computing course offerings at their schools. A rubric will be created with these factors to rank the applicants. Upon induction, each representative teacher and his/her school administrator (Principal or Assistant Principal) will be invited to meet with that programs leadership team to discuss program logistics and expectations. At this meeting, administrators must make a verbal commitment to offer AP CSP the following year and begin facilitating institutional changes necessary to support this endeavor.

\subsection{Teacher Professional Development}

For newly trained AP CSP teachers to excel in his/her role, the program must provide instructional support in both content knowledge when conducting this program. During the Spring semester, there will be a Kick-Off event where the curriculum will commence and teachers will be paired with their undergraduate mentors. This kickoff event will help conceptualize the program aim and expected results. Mentor-mentee matches will be made to best accommodate teachers' needs.Considerations will include but are not limited to: scheduling and location logistics, online/in-person preference, teachers' levels of CS content knowledge, and students' levels of content knowledge. After the Kick-Off, teachers will begin completing the APCSP online curriculum and have weekly meetings with their mentor for homework help and content support.Teachers and undergraduate mentors will establish when/where to meet, including virtual meeting options.

Teachers are encouraged to have a strong grasp of Algebra and logic to fully understand the curriculum of the APCSP course. All participants in this program will be required to move at an accelerated pace to cover 
all the material necessary to earn teaching certification by the College Board. Teachers are expected to complete the course, by taking it during when it does not interfere with their teaching schedules. Also, where it will not affect their curriculum planning for preparing students for standardized test. The teacher and undergraduate mentor portion is to be completed in a 3 to 4-month time frame, that will include a two-weeklong summer event to close the training. During this event, teachers will be able to collaborate with each other on developing effective lesson plans for their classroom. The PA will share material on how to market the course for students to sign up and remain encouraged to take the exam in May. By the conclusion of the weeklong event, teachers should have applied to receive their certification from College Board. This will then allow teachers to be certified to teach the APCSP course in their respective school. Finally, the curriculum will include information on pathways and careers in CS so that teacher will be able to advise their HS students. students. The subsequent academic year, as these teachers begin teaching AP CS courses, they will receive ongoing and in-class support from their undergraduate mentor.

\subsection{Mentor/Mentee Relationship}

Participants will complete a brief, weekly online survey to report the teacher's progress to the PA, outcomes of the mentor/mentee meeting, and to alert program staff to any relationship issues that might need attention. The PA will track teacher and student meeting preferences (in-person or virtual), duration of each meeting, and any common APCSP content-related questions. This information will be useful in gathering information to improve the program in following years. Mentors will be responsible for assessing their mentees' progress completion of the APCSPonline material and for reporting any lack in participation. Similarly, teachers will be responsible for reporting any issues with their mentor and cases of unprofessionalism. If either a teacher or a student is not actively participating in the program and fulfilling expectations, they will meet with the PA to determine the best plan of action. Options include: remediation of work, alternative mentor/mentee pairings, or termination from program if deemed necessary. If a teacher participant is removed from the program, they will be replaced the following year by another teacher from the same school.

\subsection{Materials}

The tools required for this course are all web and android device intensive. Participants in the course will need a laptop, android phone or tablet and a strong work ethic. The course itself encompasses a lot of app development using the MIT App Inventor. This is a free, cloud-based service that will be used to design programming apps for Android devices.[1] Throughout the curriculum there are app assignments that are completed by utilizing the MIT App Inventor tool and a journal that is completed using Google sites. The purpose of Google sites is used to keep an active account how certain projects were executed and any presentations that are used as post assignments.

Another part of the curriculum requires office hours to be conducted using Google hangouts. This actively allows teachers to keep track the progress of their students understanding of the projects that have been conducted. This could additionally serve the function as an evaluation process to fully grasp what students are exceeding or struggling in that unit. The information that teachers are to discover using the Google sites and hangouts is that student progress can be easily accessible. So, assignments can be found all online and teachers will have full access without having to deal with other platforms that have sign in procedures and so forth.

APCSP is fundamentally constructed by finding CS applications in the real world. Thus, a lot of reading assignments come from Blown to Bits. In those readings, teachers will find how the concepts they are practicing are further explained in selected readings. Essentially, what the book does is tie both assignments and the reading concepts to create a more in depth assignment. This is particularly vital for preparing for the end of the year Advanced Placement (AP) exam. The book is available for pdf download use, so teachers will have access to it throughout the program.

\subsection{Web Technology}

A web portal will be built to execute multiple task including the following: 1) project overview, 2) students and teacher applications to the program, 3) contact information for the project leadership, 4) links to additional coding resources for students, 5) calendar of local computing events for students and 6) dissemination of data collected and finished manuscripts/publications and posters. The website was also designed to provide answers to more informal questions that an individual may not be able to find on the Internet because these questions could also influence the likelihood of an individual later pursuing a career in computing. The website will serve as a tool for participants to go to utilizing when they find themselves stuck on different exercise sections because of the language used in the APCSP program. Since the APCSP program has sufficient step by step details on completing the assignments, the website will provide a tool to understand the purpose behind certain integrations. 
Throughout the course students and teachers must use Google sites to fully document their work. The Google site will serve as an online portfolio that is a continuously receiving input from the participants that tracks their progress throughout the course. Entries that are included but are not limited to are; difficulties encountered throughout the exercises, pre-andpost-entries on the exercises and then a link to the finish product. The benefit of this portfolio allows the PA to monitor and track the progress of the participants and to collect input on what problem areas that may arise throughout the course. The participants will then be able to see their progress from when they started the course to when they end the course.

Teachers who take this course into their respective schools will be able to utilize Google Hangouts to hold virtual office hours. This is under the discretion of the teacher because they will mold the course to fit their students. So, if hosting after-school sessions are most efficient, then using the Google Hangout web conference tool would not be needed. Participants will have presentations to give after completing certain exercises. The purpose of the presentations are to simulate an experimental design presentation where participants will explain their finished product and the roadmap they took. This can be done using a slideshow format and through Google hangouts.

\section{Research Plan}

In order to evaluate the effectiveness of the program, paper-based and online questionnaires/surveys will be used to determine the extent to which participants demonstrate gains in CS content knowledge, pedagogical content knowledge, teaching confidence, intent to persist, and ability to mentor.Participants will complete a brief monthly mentor-mentee survey to check on progress and ensure a good match. This data will be supplemented with qualitative findings from end-of- year focus groups. Finally, to measure overall success of the program, APCSP minority student performance data will be collected and compared to minority averages in the state and nation.

\section{References}

[1]. (2016). Retrieved from MIT App Inventor: http://appinventor.mit.edu/explore/hour-of-code.html

[2]. Advances in AP. (2016, December). Retrieved from Collegeboard.org: https://advancesinap.collegeboard.org/stem/computerscience-principles

[3]. AP Program Participation and Performance Data 2016. (2017). Retrieved from College Board: https://research.collegeboard.org/programs/ap/data/participation/ap-2016

[4]. Committee, K.-1. C. (2016). K-12 Computer Science Framework. ACM Digital Library, 52-157.

[5]. (2015), Computing Research News May. "Continued Booming Undergraduate CS Enrollment; Doctoral Degree Production Dips Slightly." 2015 Taulbee Survey 28.5 (2015): n. pag. The Taulbee Survey. Computing Research Association.

[6]. Georgia Department of Education. (2016, October 04). Retrieved from https://app3.doe.k12.ga.us/owsbin/owa/fte_pack_ethnicsex.entry_form

[7]. Step-by-step access to Census Information. (2015). Retrieved March 3, 2017, from www.factfinder.census.gov: https://factfinder.census.gov/faces/tableservices/jsf/pages/productview.xhtml?pid=ACS_15_5YR_B14006\&prodType=table 